\title{
Oyster crude polysaccharides attenuates lipopolysaccharide-induced cytokines production and PPARY expression in weanling piglets
}

\author{
Guangwen Yin ${ }^{1}$, Juhui Huang ${ }^{1}$, Maotao Ma ${ }^{1}$, Xun Suo ${ }^{2}$ and Zhijian Huang ${ }^{\text {* }}$
}

\begin{abstract}
This study evaluated whether oyster crude polysaccharides (OPS) attenuates lipopolysaccharide (LPS)-induced immune stress in weanling piglets. Thirty healthy crossbred piglets ( $28 \pm 1$ days old) were randomly divided into five groups (6 piglets/group). Blank control and LPS groups were fed with the basal diet, while low, medium and high dose of OPS groups were fed with the basal diet supplemented with $0.5,0.8$ and $1.2 \%$ OPS, respectively, for 30 days. LPS group, as well as low, medium and high dose of OPS groups were then injected intraperitoneally with LPS $(100 \mu \mathrm{g} / \mathrm{kg}$ body weight), whereas the blank control group was given phosphate buffered saline. The concentrations of TNF- $\alpha$, IL-1 $\beta$ and IL- 6 in plasma were detected by ELISA. The mRNA levels of PPARY in liver, spleen, adrenal gland and thymus were evaluated by quantitative real-time PCR. The results showed that compared with the blank control, LPS treatment significantly increased plasma IL-1 $\beta$, IL-6 and TNF-a levels, which was significantly attenuated by supplementing $0.5,0.8$ or $1.2 \%$ OPS in the diet. In addition, LPS significantly induced expression of PPARY mRNA in liver, spleen, adrenal gland, and thymus, which was blocked by adding OPS regardless of the doses. These results indicate that dietary supplementation of OPS was able to alleviate the immune stress induced by LPS.
\end{abstract}

Keywords: Oyster polysaccharides, Immune stress, Cytokines, PPARy, Piglets

\section{Background}

Proinflammatory cytokines including interleukin-1 (IL1 ), interleukin-6 (IL-6), and tumor necrosis factor- $\alpha$ $(\mathrm{TNF}-\alpha)$ promote systemic inflammation (Cagiola et al. 2006; Cook et al. 2011; Johnson 1997; Webel et al. 1997). Because of their proinflammatory activity, these cytokines may make a disease deteriorated by producing inflammation and tissue damage, leading to shock or death (Baggio et al. 2005; Netea et al. 2003). Previous studies have shown that in response to LPS challenge, the proinflammatory cytokines can be induced, reducing feed intake and growth in pigs (Johnson and von Borell

\footnotetext{
*Correspondence: hzjfacu@163.com; huangzj1999@sina.com ${ }^{1}$ Engineering Laboratory of Animal Pharmaceuticals and College of Animal Science, Fujian Agriculture and Forestry University, Fuzhou 350002, Fujian Province, China

Full list of author information is available at the end of the article
}

1994). Lipopolysaccharide (LPS), an endotoxin, is the major component of the outer membrane of Gram-negative bacteria such as Escherichia coli (E. coli). Administration of LPS in animals is a well-documented model for immune stress (Escribano et al. 2014). LPS exerts its effect through stimulating numerous cell types, such as macrophages, to produce pro-inflammatory cytokines, including TNF $\alpha$, IL1 $\beta$ and IL6 (Webel et al. 1998; Dinarello 1996).

Peroxisome proliferator activated receptor gamma (PPARY), a transcriptional factor, belongs to the ligand-activated nuclear receptor super family, and is expressed virtually in all kinds of cells, including macrophages, dendritic cells, $\mathrm{T}$ and $\mathrm{B}$ cells (Yang et al. 2008). PPAR $\gamma$ was originally found to regulate adipocyte differentiation and lipid metabolism (Liu et al. 2008; Monsalve et al. 2013; Mueller et al. 2003). However, accumulating evidence has implicated that PPAR $\gamma$ 
also plays an important role in the regulation of proinflammatory cytokine production, and contributes to the therapeutic effects on inflammatory diseases (Jacob et al. 2007; Kim et al. 2012). Activation of PPAR $\gamma$ has been shown to inhibit cytokine production by preventing activation and translocation of NF- $\mathrm{KB}$ ( $\mathrm{Li}$ and Palinski 2006; Touyz and Schiffrin 2006).

The pacific oyster Crassostrea gigas (C. gigas) is a common aquaculture species widely consumed in many countries. The oyster is a rich source of dietary protein and other nutrients, such as carbohydrates, lipids, polyunsaturated fatty acids and minerals (Pennarun et al. 2003; Cheng et al. 2013). It has been described that the extract of $C$. gigas exhibits antioxidant activity (Watanabe et al. 2012). Recently, a phenolic antioxidant from the oyster has been identified (Watanabe et al. 2012; Yoshikawa et al. 1997). Strong evidence has demonstrated that polysaccharides derived from yeast and medicinal mushrooms possess immunomodulatory activity (Cheng et al. 2013). Feeding $\beta$-glucans can stimulate both specific and nonspecific immune responses in mice (Yun et al. 2003). Additionally, polysaccharides from aloe can also inhibit the inflammatory response (Strickland et al. 1999).

Although many studies have shown the immunomodulatory activities of polysaccharides, most of them focus on fungal polysaccharides. To date, limited evidence is available pertaining to the immunomodulatory activity of polysaccharides derived from animal origins. As the extract of $C$. gigas contains a considerable amount of carbohydrates (Cheng et al. 2013), we hypothesized that OPS may alter the immune response in weanling piglets. To test this hypothesis, here we investigated whether OPS attenuates LPS-induced cytokines production and PPAR $\gamma$ expression in weanling piglets.

\section{Methods}

\section{Animals and treatments}

Oyster crude polysaccharide (OPS) was provided by Addison Biological Technology (Beijing, China). Crossbred healthy piglets, weighing $9.91 \pm 1.38 \mathrm{~kg}$ and aged $28 \pm 1$ days, were castrated and randomly divided into five groups (namely blank control, LPS control, low OPS, medium OPS, high OPS groups) with six replicates per group. The piglets in the blank control group and LPS group were only fed the basal diet (Table 1), whereas the animals in the OPS low, medium and high groups were fed the basal diet supplemented with $0.5,0.8$ and $1.2 \%$ OPS, respectively. All groups were fed with the above diets for 30 days. Then the animals were weighed and intraperitoneally injected once with either phosphate buffered saline (PBS) (only for blank control group) or
Table 1 Composition of experimental diets

\begin{tabular}{lllr}
\hline Item & \multicolumn{3}{c}{ Item } \\
\hline $\begin{array}{lll}\text { Ingredient, \% } \\
\text { Corn }\end{array}$ & \multicolumn{3}{c}{ Nutrient level, \% } \\
Farina & 9 & Crude protein & 19.52 \\
Liquid feed oil & 2 & Crude fiber & 2.82 \\
Soybean meal & 21.3 & Calcium fat & 4.72 \\
Fermented soybean meal & 5 & Phosphorus & 0.75 \\
Fish meal & 3 & Dry matter & 0.54 \\
Glucose & 2 & Digestive energy $(\mathrm{MJ} / \mathrm{kg})$ & 14.3 \\
Sugar & 2 & Lysine & 1.33 \\
Vitamin-mineral mix & 6 & &
\end{tabular}

a The vitamin and mineral premix provided the following (per kg of diet): vitamin A, 10,165 IU; vitamin D3, $1007 \mathrm{IU}$; vitamin E, 75 IU; Zn, 2133 mg; Fe, $296 \mathrm{mg}$; Mn, $45 \mathrm{mg}$; Cu, $134 \mathrm{mg}$; Co, $0.31 \mathrm{mg}$; and Se, $0.5 \mathrm{mg}$

LPS $(100 \mu \mathrm{g} / \mathrm{kg}$ body weight). The LPS (E. coli serotype O55:B5 phenol extract; Cat.\# L-2630, Sigma-Aldrich, St. Louis, MO) was dissolved in PBS solution (Cat.\# P-4417, Sigma-Aldrich) to make $0.4 \mathrm{mg} / \mathrm{ml}$ LPS solution. Three hours post injection, all piglets were euthanized for blood and tissue sampling. Six piglets from each treatment were sacrificed after feed deprivation for $12 \mathrm{~h}$ by injecting $4 \%$ sodium pentobarbital solution ( $40 \mathrm{mg} / \mathrm{kg}$ body weight) for the collection of tissue samples on day 30 post weaning. The animal protocol was approved by the Animal Care Committee of Fujian Agriculture and Forestry University.

\section{Blood sampling and preparation}

Blood samples ( $10 \mathrm{ml}$ per piglet) were collected from the precaval vein. Each sample was drawn into a plastic tube with liquaemin and centrifuged at $3000 \times g$ for $10 \mathrm{~min}$ at room temperature. The plasma obtained was stored at $-20^{\circ} \mathrm{C}$ until analysis for cytokines.

\section{Tissue sampling and preparation}

Approximately $1 \mathrm{~g}$ of liver, adrenal gland, thymus or spleen was collected immediately, frozen in liquid nitrogen, and stored at $-80{ }^{\circ} \mathrm{C}$ until the extraction of total RNA.

\section{Analysis of IL-1 $\beta$, IL- 6 , and TNF- $\alpha$ concentrations}

Concentrations of IL-1 $\beta$, IL- 6 , and TNF- $\alpha$ in the plasma were measured using ELISA kits (Cusabio Biotech Co., Wuhan, China), according to the manufacturer's instructions. The sensitivity of all assays was $3 \mathrm{pg} / \mathrm{ml}$.

\section{Quantitative real-time PCR}

Total RNA was extracted from the samples using Trizol reagent (Invitrogen, Carlsbad, CA). The final RNA was eluted in an appropriate amount of $0.1 \%$ diethyl 
pyrocarbonate (DEPC) treated water (Sigma-Aldrich). For each sample, the integrity of RNA extracted was confirmed in agarose gel electrophoresis by staining with ethidium bromide and visualizing under UV light. The amount of RNA extracted was determined, and its purity (OD260/OD280 ratio between 1.8 and 2.2) was verified using an ND-1000 spectrophotometer (NanoDropTechnologies, Wilmington, DE, USA). The cDNA was synthesized using random primers and a High Capacity cDNA Reverse Transcription Kit (Applied Biosystems, Foster City, CA, USA). The primer pairs used for analysis of specific genes (Table 2) were designed with the PerlPrimer software (perlprimer.sourceforge.net). Quantitative realtime PCR was performed on the 7500 Real Time PCR System (Applied Biosystems) with a program of $50{ }^{\circ} \mathrm{C}$ for $2 \mathrm{~min}, 95^{\circ} \mathrm{C}$ for $10 \mathrm{~min}$ and 40 cycles of $95^{\circ} \mathrm{C}$ for $15 \mathrm{~s}$, and $60{ }^{\circ} \mathrm{C}$ for $1 \mathrm{~min}$. For each sample, template copy numbers were internally normalized with their respective input control. Relative expression was calculated as the ratio of template copy numbers of a sample relative to the naive control after normalizing to their respective isotype control $\beta$-actin (Huang et al. 2011).

\section{Statistical analysis}

Values were expressed as mean $\pm \mathrm{SD}$. Data were subjected to one-way analysis of variance (ANOVA) to determine whether significant differences occurred in pig fed the different diets. If a significant difference was identified, differences among means were compared by Tukey's multiple range tests $(\mathrm{P}<0.05)$. Statistical analysis was performed using the Statistica software package (Version 6.0, Statsoft, Tulsa, OK, USA).

\section{Results}

\section{OPS attenuates LPS-induced cytokines production} in piglets

As shown in Table 3, treatment of piglets with LPS significantly elevated the plasma concentrations of IL-1 $\beta$, IL-6 and TNF- $\alpha(P<0.05)$, compared with the blank control (PBS), suggesting that LPS did induce immune stress. Of interest, the LPS-induced immune stress was significantly attenuated by adding low $(0.5 \%)$, medium $(0.8 \%)$, or high dose of OPS $(1.2 \%)(P<0.05)$. There was no significant difference between medium OPS group and low

\section{Table 2 Primers for real-time PCR}

\begin{tabular}{llll}
\hline Gene & Primers & $\begin{array}{l}\text { Product } \\
\text { Size (bp) }\end{array}$ & $\begin{array}{l}\text { Efficiency } \\
\text { (\%) }\end{array}$ \\
\hline PPARY & F: CTGACCAAAGCAAAGGCG & 191 & 102 \\
& R: TCCACGGAGCGAAACTGA & & \\
$\beta$-actin & F: CCAGGTCATCACCATCGGC & 152 & 103 \\
& R: TGGCGTAGAGGTCCTTGCG & & \\
\hline
\end{tabular}

Table 3 Effect of OPS on LPS-induced protein expression of IL-1 $\beta$, IL- 6 and TNF- $\alpha$ in the plasma of piglets

\begin{tabular}{lllc}
\hline Group & IL-1 $\boldsymbol{\beta}$ & IL-6 & \multicolumn{1}{l}{ TNF- $\boldsymbol{a}$} \\
\hline Blank control & $12.50 \pm 2.80^{\mathrm{b}}$ & $2.14 \pm 0.06^{\mathrm{c}}$ & $81.55 \pm 5.50^{c}$ \\
LPS control & $32.62 \pm 12.53^{\mathrm{a}}$ & $2.48 \pm 0.09^{\mathrm{a}}$ & $166.65 \pm 20.88^{\mathrm{a}}$ \\
Low OPS & $11.68 \pm 3.27^{\mathrm{b}}$ & $2.09 \pm 0.13^{\mathrm{c}}$ & $77.62 \pm 7.82^{\mathrm{c}}$ \\
Medium OPS & $11.03 \pm 2.06^{\mathrm{b}}$ & $2.02 \pm 0.07^{\mathrm{c}}$ & $86.14 \pm 3.83^{\mathrm{c}}$ \\
High OPS & $12.14 \pm 2.55^{\mathrm{b}}$ & $2.34 \pm 0.06^{\mathrm{b}}$ & $107.85 \pm 6.61^{\mathrm{b}}$ \\
\hline
\end{tabular}

Different letters in the same rank represent significant difference between the treatments $(P<0.05)$, while the same letter in the same rank means no significant difference between the treatments $(P>0.05)$. The units for IL-1 $\beta$, IL-6 and TNF- $a$ in the table $(\mathrm{pg} / \mathrm{ml})$

OPS group, in terms of the levels of the proinflammatory cytokines. To our surprise, 0.5 and $0.8 \%$ OPS inhibited LPS-induced IL- 6 and TNF- $\alpha$ more potently than $1.2 \%$ OPS $(P<0.05)$.

\section{OPS attenuates LPS-induced expression of PPAR $\gamma$ mRNA in piglets}

As shown in Fig. 1, treatment of piglets with LPS significantly increased expression of PPAR $\gamma$ mRNA in liver, adrenal gland, thymus and spleen, compared with the blank control (PBS) $(P<0.05)$. LPS-induced PPAR $\gamma$ expression was significantly attenuated by adding low $(0.5 \%)$, medium $(0.8 \%)$, or high dose of OPS (1.2\%). It appeared that the effect of OPS on LPS-induced PPAR expression was independent of concentrations of OPS used in the experiment.

\section{Discussion}

Immune stress induces production of proinflammatory cytokines in the body, which can decrease growth rate, and accelerate degradation of body protein. Therefore, immune stress can cause significant economic loss to

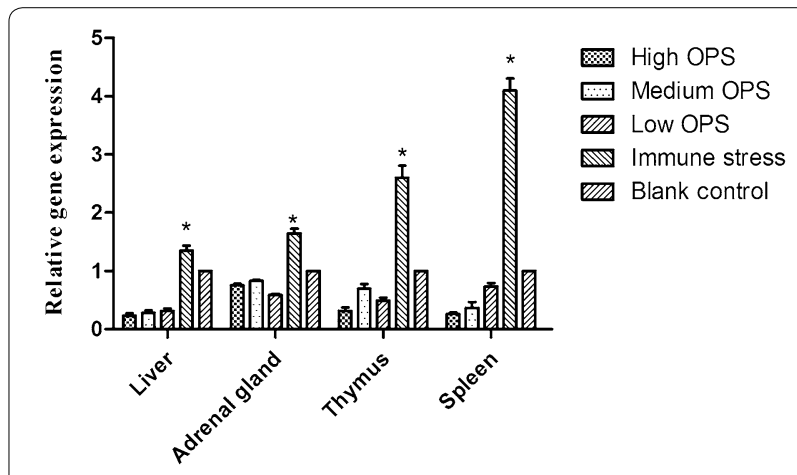

Fig. 1 Effect of OPS on LPS-induced PPARY mRNA expression in liver, adrenal gland, thymus, and spleen of piglets. Experiments were performed in duplicate and repeated in at least three independent experiments using tissues from 6 individual piglets. Results are expressed as mean \pm SEM. ${ }^{*} P<0.05$ 
livestock producers (Tuchscherer et al. 2002). Previous studies have shown that the proinflammatory cytokines TNF $\alpha$, IL- 6 , and IL- $1 \beta$ are elevated in plasma in response to peripheral LPS injection in weaned pigs (Chirullo et al. 2015; Webel et al. 1997). Here we found that an intraperitoneal injection of LPS in weaned piglets increased the levels of TNF $\alpha$, IL-6, and IL- $1 \beta$ in the plasma, which is consistent with the previous findings (Wright et al. 2000; Webel et al. 1997). Interestingly, LPS-induced elevation of IL-1 $\beta$, IL- 6 and TNF $\alpha$ levels was significantly attenuated by supplementing OPS in the diet, indicating that OPS may play an anti-inflammatory role in the immune stress caused by LPS. OPS may reduce the expression of TLR4, a receptor for LPS, on immune-related cells, then attenuate the release of proinflammatory cytokines. In the present study, we noticed that the inhibitory effect of the high dose (1.2\%) of OPS on LPS-induced cytokines was weaker than that of the low $(0.5 \%)$ or the medium dose $(0.8 \%)$ of OPS. Our explanation is that high dose of OPS may change the palatability of the diet, and the feed intake of pigs, leading to the reduced absorptive capacity of OPS. Further research is needed to address this question.

Recently, the anti-inflammatory properties of the nuclear hormone receptor family known as peroxisome proliferator-activated receptors (PPARs) have emerged, although they were originally found to be implicated in obesity, diabetes, and atherosclerosis. PPAR $\gamma$ can be activated by specific agonists, and then translocate to the nucleus to regulate the transcription of specific genes. Activation of PPARy can protect cells from injury by its anti-inflammatory and immunomodulatory effects (Belvisi and Hele 2008). Growing evidence suggests that the benefits of PPAR $\gamma$ agonists may also be derived from their anti-inflammatory properties (Celinski et al. 2013; Hanks et al. 2010). To date, however, limited evidence is available pertaining to the anti-inflammatory properties of PPARy in pigs. We found that LPS was able to induce the expression of PPARY in many tissues of piglets. The high level of expression of PPAR $\gamma$ mRNA induced by LPS implies that PPAR $\gamma$ may regulate inflammation in pigs. The trend was in line with the concentrations of the proinflammatory cytokines in the plasma. Our result is consistent with the previous report that LPS can increase the expression of PPAR $\gamma$ in the white blood cells of pigs (Leininger et al. 1999). In the present study, we found that pigs fed OPS had lower expression of PPAR $\gamma$, indicating that OPS may play an important role in negatively regulating the expression of PPARy and the production of the pro-inflammatory cytokines. OPS may influence the expression of PPAR $\gamma$ and TLR4 on monocytes or macrophages, then regulate the production of proinflammatory cytokines after LPS-stimulation. Further research is needed to shed the light on the mechanisms whereby OPS reduces th expression of proinflammatory cytokines.

\section{Conclusion}

In conclusion, dietary supplementation of OPS was able to alleviate the immune stress induced by LPS, and the observed effects after the administration of OPS are concentrations used in the experiment independent.

\section{Authors' contributions}

GWY performed the experiments and wrote the manuscript. JHH and MMT executed the experiment and analyzed the sera and tissue samples. ZJH and XS conceived and designed the study. All authors read and approved the final manuscript.

\section{Author details \\ ${ }^{1}$ Engineering Laboratory of Animal Pharmaceuticals and College of Animal Science, Fujian Agriculture and Forestry University, Fuzhou 350002, Fujian Province, China. ${ }^{2}$ National Animal Protozoa Laboratory and College of Veteri- nary Medicine, China Agricultural University, Beijing 100193, China.}

\section{Acknowledgements}

We thank Dr. Shile Huang (Louisiana State University Health Sciences Center, USA) for reading the manuscript. This study was supported by Key Project of the Science and Technology Department of Fujian Province (2015N0017), Natural Science Foundation of Fujian Province (2015J01075) and the National Natural Science Foundation of China (31502058).

\section{Competing interests}

The authors declare that they have no competing interests.

Received: 6 October 2015 Accepted: 10 May 2016

Published online: 23 May 2016

\section{References}

Baggio V, Ott F, Fischer RW, Gram H, Peele J, Spreng D, Schmokel H, Jungi TW (2005) Production of antibodies to canine IL-1 beta and canine TNF to assess the role of proinflammatory cytokines. Vet Immunol Immunopathol 107(1-2):27-39

Belvisi MG, Hele DJ (2008) Peroxisome proliferator-activated receptors as novel targets in lung disease. Chest 134(1):152-157

Cagiola M, Giulio S, Miriam M, Katia F, Paola P, Macri A, Pasquali P (2006) In vitro down regulation of proinflammatory cytokines induced by LPS tolerance in pig CD14 ${ }^{+}$cells. Vet Immunol Immunopathol 112(3-4):316-320

Celinski K, Dworzanski T, Fornal R, Korolczuk A, Madro A, Brzozowski T, Slomka M (2013) Comparison of anti-inflammatory properties of peroxisome proliferator-activated receptor gamma agonists rosiglitazone and troglitazone in prophylactic treatment of experimental colitis. J Physiol Pharmacol 64(5):587-595

Cheng JY, Ng LT, Lin CL, Jan TR (2013) Pacific oyster-derived polysaccharides enhance antigen-specific Thelper (Th)1 immunity in vitro and in vivo. Immunopharmacol Immunotoxicol 35(2):235-240

Chirullo B, Pesciaroli M, Drumo R, Ruggeri J, Razzuoli E, Pistoia C, Petrucci P, Martinelli N, Cucco L, Moscati L, Amadori M, Magistrali CF, Alborali GL, Pasquali P (2015) Salmonella Typhimurium exploits inflammation to its own advantage in piglets. Front Microbiol 6:985. doi:10.3389/ fmicb.2015.00985

Cook VL, Holcombe SJ, Gandy JC, Corl CM, Sordillo LM (2011) Ethyl pyruvate decreases proinflammatory gene expression in lipopolysaccharide-stimulated equine monocytes. Vet Immunol Immunopathol 141(1-2):92-99

Dinarello CA (1996) Biologic basis for interleukin-1 in disease. Blood 87(6):2095-2147

Escribano D, Campos PH, Gutierrez AM, Le Floc'h N, Ceron JJ, Merlot E (2014) Effect of repeated administration of lipopolysaccharide on inflammatory and stress markers in saliva of growing pigs. Vet J 200(3):393-397 
Hanks BC, Kuroki K, Stoker AM, Cook JL (2010) Evaluation of anti-inflammatory and chondroprotective effects of peroxisome proliferator-activated receptor gamma agonists in cartilage and synovial explants from dogs. Am J Vet Res 71(10):1142-1147

Huang X, Zou J, Xu H, Ding Y, Yin G, Liu X, Suo X (2011) Transgenic Eimeria tenella expressing enhanced yellow fluorescent protein targeted to different cellular compartments stimulated dichotomic immune responses in chickens. J Immunol 187(7):3595-3602

Jacob A, Wu R, Zhou M, Wang P (2007) Mechanism of the anti-inflammatory effect of curcumin: PPAR-gamma activation. PPAR Res 2007:89369

Johnson RW (1997) Inhibition of growth by pro-inflammatory cytokines: an integrated view. J Anim Sci 75(5):1244-1255

Johnson RW, von Borell E (1994) Lipopolysaccharide-induced sickness behavior in pigs is inhibited by pretreatment with indomethacin. J Anim Sci 72(2):309-314

Kim JC, Lee YH, Yu MK, Lee NH, Park JD, Bhattarai G, Yi HK (2012) Anti-inflammatory mechanism of PPARgamma on LPS-induced pulp cells: role of the ROS removal activity. Arch Oral Biol 57(4):392-400

Leininger MT, Portocarrero CP, Houseknecht KL (1999) Peroxisome proliferatoractivated receptor gamma1 expression in porcine white blood cells: dynamic regulation with acute endotoxemia. Biochem Biophys Res Commun 263(3):749-753

Li AC, Palinski W (2006) Peroxisome proliferator-activated receptors: how their effects on macrophages can lead to the development of a new drug therapy against atherosclerosis. Annu Rev Pharmacol Toxicol 46:1-39

Liu Y, Lu J, Shi J, Hou Y, Zhu H, Zhao S, Liu H, Ding B, Yin Y, Yi G (2008) Increased expression of the peroxisome proliferator-activated receptor gamma in the immune system of weaned pigs after Escherichia coli lipopolysaccharide injection. Vet Immunol Immunopathol 124(1-2):82-92

Monsalve FA, Pyarasani RD, Delgado-Lopez F, Moore-Carrasco R (2013) Peroxisome proliferator-activated receptor targets for the treatment of metabolic diseases. Mediat Inflamm 2013:549627

Mueller C, Weaver V, Vanden Heuvel JP, August A, Cantorna MT (2003) Peroxisome proliferator-activated receptor gamma ligands attenuate immunological symptoms of experimental allergic asthma. Arch Biochem Biophys 418(2):186-196

Netea MG, van der Meer JWM, van Deuren M, Kullberg BJ (2003) Proinflammatory cytokines and sepsis syndrome: not enough, or too much of a good thing? Trends Immunol 24(5):254-258
Pennarun AL, Prost C, Haure J, Demaimay M (2003) Comparison of two microalgal diets. 1. Influence on the biochemical and fatty acid compositions of raw oysters (Crassostrea gigas). J Agric Food Chem 51(7):2006-2010

Strickland FM, Darvill A, Albersheim P, Eberhard S, Pauly M, Pelley RP (1999) Inhibition of UV-induced immune suppression and interleukin-10 production by plant oligosaccharides and polysaccharides. Photochem Photobiol 69(2):141-147

Touyz RM, Schiffrin EL (2006) Peroxisome proliferator-activated receptors in vascular biology-molecular mechanisms and clinical implications. Vascul Pharmacol 45(1):19-28

Tuchscherer M, Kanitz E, Otten W, Tuchscherer A (2002) Effects of prenatal stress on cellular and humoral immune responses in neonatal pigs. Vet Immunol Immunopathol 86(3-4):195-203

Watanabe M, Fuda H, Jin S, Sakurai T, Ohkawa F, Hui SP, Takeda S, Watanabe T, Koike T, Chiba H (2012) Isolation and characterization of a phenolic antioxidant from the Pacific oyster (Crassostrea gigas). J Agric Food Chem 60(3):830-835

Webel DM, Finck BN, Baker DH, Johnson RW (1997) Time course of increased plasma cytokines, cortisol, and urea nitrogen in pigs following intraperitoneal injection of lipopolysaccharide. J Anim Sci 75(6):1514-1520

Webel DM, Mahan DC, Johnson RW, Baker DH (1998) Pretreatment of young pigs with vitamin E attenuates the elevation in plasma interleukin-6 and cortisol caused by a challenge dose of lipopolysaccharide. J Nutr 128(10):1657-1660

Wright KJ, Balaji R, Hill CM, Dritz SS, Knoppel EL, Minton JE (2000) Integrated adrenal, somatotropic, and immune responses of growing pigs to treatment with lipopolysaccharide. J Anim Sci 78(7):1892-1899

Yang XY, Wang LH, Farrar WL (2008) A role for PPARgamma in the regulation of cytokines in immune cells and cancer. PPAR Res 2008:961753

Yoshikawa T, Naito Y, Masui K, Fujii T, Boku Y, Nakagawa S, Yoshida N, Kondo M (1997) Free radical-scavenging activity of Crassostera gigas extract (JCOE). Biomed Pharmacother 51(8):328-332

Yun CH, Estrada A, Van Kessel A, Park BC, Laarveld B (2003) Beta-glucan, extracted from oat, enhances disease resistance against bacterial and parasitic infections. FEMS Immunol Med Microbiol 35(1):67-75

\section{Submit your manuscript to a SpringerOpen ${ }^{\odot}$ journal and benefit from:}

- Convenient online submission

- Rigorous peer review

- Immediate publication on acceptance

- Open access: articles freely available online

- High visibility within the field

- Retaining the copyright to your article

Submit your next manuscript at springeropen.com 